\title{
Changes in Soluble Sugars, Sugar Profile, Starch and Proline in Developing Coconut (Cocos nucifera L.) Inflorescences
}

\author{
Bandupriya H.D.D. , Weerakoon L.K., Ranasinghe C.S., Fernando W.P.K.K.
}

\begin{abstract}
Changes in soluble sugars, sugars profile, starch and proline levels in inflorescence rachillae from individual coconut palms were investigated during inflorescence development with the aim of determining a possible correlation between these characters and morphogenic potential of inflorescence tissues. Rachillae for analysis were collected from unopened inflorescences of -1 to -13 stages (considering the youngest open inflorescence as 0 stage) in decreasing order of maturity ( -1 stage is the most mature stage whereas -13 is the most immature stage). Important differences among the maturity stages were observed for total sugars. In very tender inflorescences (-13 and -12$)$, the total sugar content was very low whereas a gradual increase was observed from -11 to -7 stages, with -7 stage having the highest level. The total sugar content in more mature inflorescences was relatively low, with the exception of -2 stage, which had a high total sugar content. In regard to sugar profiles, sucrose, fructose and glucose were the main soluble sugars present in coconut inflorescence and sucrose was the most abundant sugar in -5 to -9 maturity stages. Total soluble sugars and sucrose in maturity stages from -5 to -9 showed a very similar variation and significantly higher levels of sucrose were observed in -6 to -8 stages. The proline content in the mature stages, -1 to -3 , was significantly lower than in the other stages with no significant variation in the stages -4 to -11 . The pattern of variation in starch content was similar to that of proline which decreased with increasing maturity of inflorescence. In view of the results obtained, the higher accumulation of sucrose and total sugars in -6 , -7 and -8 stages may have some significance in morphogenesis, especially as an energy source. The 10 $\mathrm{cm}$ length inflorescence that responds better for callusing falls within this range. Thus total sugar and sucrose content may be possible biochemical markers for assessing the morphogenic potential of inflorescence explants.
\end{abstract}

Keywords: Coconut, inflorescence, maturity stage, total sugar, proline, sucrose, starch.

Coconut Research Institute, Lunuwila, 65150, Sri Lanka.

*Correspondence author: dbandupriya @yahoo.com 


\section{Introduction}

The coconut palm (Cocos nucifera L.) plays an important role as a subsistence crop and a commercial oil crop in largely tropical regions. Being an out breeding plant that is propagated only by seeds, coconut palm exhibits great variability in selected characters. Vegetative propagation of improved varieties would result in increased production and homogeneity in coconut lands. Tissue culture is the only possible approach to achieve this goal.

Immature inflorescence that contains numerous meristematic points is a promising source of explants for in vitro culture. Somatic embryogenesis in inflorescence tissues was first reported in 1983 (Branton and Blake, 1983) However, response of these explants under in vitro conditions is very poor and only a few plants have been regenerated from immature inflorescence derived callus (Verdeil et al, 1994; Hornung and Verdeil, 1999). One of the major constraints associated with immature inflorescence culture is the difficulty in selecting the correct developmental stage for in vitro culture. This is vital as physiological maturity of explants is known to be a determining factor of the regeneration potential (Barker et al 1999; Rodrigues-Otubo et al 2000). At present, the suitable development stage is assessed based on a morphological feature, which is the length of the inflorescence and explants which are collected from inflorescences of about $10 \mathrm{~cm}$ length. However, better criteria are needed for the selection of the most responsive stage of inflorescence for in vitro culture. Biochemical characterization of immature inflorescence explants at different stages of development could provide valuable clues in this regard.

The importance of carbohydrates in flower bud formation and development has been emphasized by numerous reports (Olley et al, 1996; Ranwala and Miller, 1998; Ito et al, 2002) Sucrose plays an important role in plant metabolism as an important storage sugar and the main form of reduced carbon translocated from chloroform was added to the supernatant and shaken thoroughly. The mixture was incubated source leaves to developing growth centers in plant (Ranwala and Miller, 1998). There is evidence to suggest that sucrose promotes flowering in most species (Bernie et al, 1998). Little is known of the biochemical changes that take place during the development of coconut inflorescence. In the present study, accumulation of certain biochemicals (Soluble sugars, proline and starch) in a series of inflorescences of different maturity stages investigated with the aim of determining a possible correlation between these variables and morphogenic potential of the explants.

\section{Materials and Methodology}

\section{Extraction and quantification of total sugars, proline and starch}

Samples from a series of inflorescence rachillae of different maturity stages ( -1 to -13 , considering the youngest open inflorescence as $0 ;-1$ is the inflorescence that is to be opened next. Thus the most mature stage is -1 whereas the most immature stage is -13 ) were collected from Sri Lanka Tall coconut palms (Figure 1). Each sample was oven dried for $48 \mathrm{~h}$ at $60^{\circ} \mathrm{C}$ and the dried samples were finely powdered using a mortar and pestle. A sample of $0.0008 \mathrm{~g}$ $-0.2000 \mathrm{~g}$ was placed in $15 \mathrm{~mL}$ of $80 \%$ ethanol (analytical reagent, BDH laboratory supplies, UK) for 25 minutes in a water bath at $60^{\circ} \mathrm{C}$. The extracts of mature inflorescences (-5 to -1$)$ contained phenolic compounds and it hindered the quantification of proline and total sugars. Therefore, polyclar (insoluble PVP) was added to the samples at 1: 0.5 ratios before adding alcohol. Each sample was then transferred to a centrifuge tube and subsequently washed with 2 $\mathrm{mL}$ of $80 \%$ ethanol. The suspension was then centrifuged (Kubota-5100 table top centrifuge, Kubota corporation, 29-9, Tokyo, Japan) for 10 min at $3500 \mathrm{rpm}$ and the supernatant was decanted. The residue was saved for analysis of starch. Five milliliters of distilled water and 10 $\mathrm{mL}$ of

at room temperature for $2 \mathrm{~h}$ for separation of the aqueous layer and the organic layer. The upper 
aqueous layer containing water soluble compounds was concentrated to a volume of 5 $\mathrm{mL}$ using a rotor- evaporator (Rotavapor RE-111 with Buchi 461 water bath, LaboratoriumsTechnik, Flawil, Switzerland) for sugar and proline assay. Total sugars were analysed using $20 \mu \mathrm{L}$ of the above extract. Distilled water was added to make the total volume up to $1 \mathrm{~mL}$. Then $1 \mathrm{~mL}$ of $5 \%$ phenol and $5 \mathrm{~mL}$ of concentrated $\mathrm{H}_{2} \mathrm{SO}_{4}$ was added to the mixture and absorbance was measured at $490 \mathrm{~nm}$ using a spectrophotometer (Dubois et al., 1956).

The residue was re-suspended in $10 \mathrm{~mL}$ of distilled water and boiled for $20 \mathrm{~min}$ in a water bath and allowed to cool to room temperature. After adding $2 \mathrm{~mL}$ of amylase, the mixture was incubated overnight at $42^{\circ} \mathrm{C}$ in a water bath. The mixture was centrifuged at $3500 \mathrm{rpm}$ for $10 \mathrm{~min}$. and the supernatant was collected to determine the starch content.

For quantification of proline, $0.5 \mathrm{~mL}$ of distilled water, $1.0 \mathrm{~mL}$ of glacial acetic acid and $1.0 \mathrm{~mL}$ of acetic ninhydrin were added to $500 \mu \mathrm{l}$ of the extract. After keeping the mixture in a boiling water bath for $45 \mathrm{~min}, 3.0 \mathrm{~mL}$ of toluene was added. Absorbance of the organic layer was measured at $515 \mathrm{~nm}$.

\section{Analysis of sugar profile}

Based on the results of previous analysis, another set of rachillae sample were collected from inflorescences of -5 to -9 stages from 20 palms for analysis of total sugar and sugars profile. Extraction of sugars was done as described in the previous section. Each sample was diluted 2 times, purified using a sep-pak cartridge and analysed for sugars (glucose, fructose, sucrose and total sugar) using a high performance liquid chromatography (HPLC) system (Waters, USA) with a sugar-pak column.

Data were collected from 4 replicated samples in the first analysis and from 20 replicated samples in the sugar profile analysis. Analysis of variance was carried out to test the significant difference between the samples of different maturity stages. When analysis of variance showed treatment effects, the Duncan's Multiple Range Test was applied to make comparisons between means at the 0.01 and 0.05 levels of significance.

\section{Results and Discussion}

A significant variation in the levels of proline, starch and total sugar was observed in inflorescence tissues of different stages of maturity (Table 1). The proline content in the more mature stages, -1 to -3 , was significantly lower than in the other stages whereas no significant variation was observed in the stages from -4 to -11 . The highest level of proline was observed in the stage -12 . The proline level was higher in younger stages and it decreased with increasing matuarity. A similar observation has been made by Claussen (2005). Studies on proline accumulation in growing leaves of tomato indicated that proline levels were higher in young leaves and decreased with increasing leaf age. Accumulation of proline has been observed in many plant species under stress conditions (Hare et al, 1999). It is considered as a compatible solute that protects folded protein structures against denaturation, stabilizes cell membranes by interacting with phospholipids, functions as a hydroxyl radical scavenger, or serves as an energy and nitrogen source (Samaras et al., 1995).

The pattern of variation in starch content was similar to that of proline which decreased with increasing maturity of inflorescence (Table 1). Stages -13 to -8 had relatively higher levels of starch. Starch accounted for more than $40 \%$ of the dry weight of the inflorescences in these

Figure 1: Coconut inflorescences from -1 stage to -13 spathes. (b) After removing the external sp

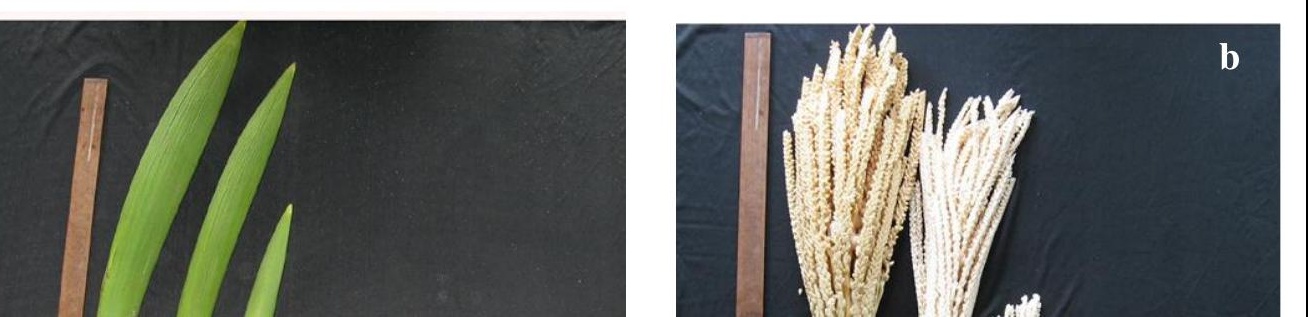


Figure 2: Concentrations of sucrose, fructose, glucose and total sugar (g/g dry weight) in inflorescence rachillae at different maturity stages. Each bar represents mean of twenty replicates.

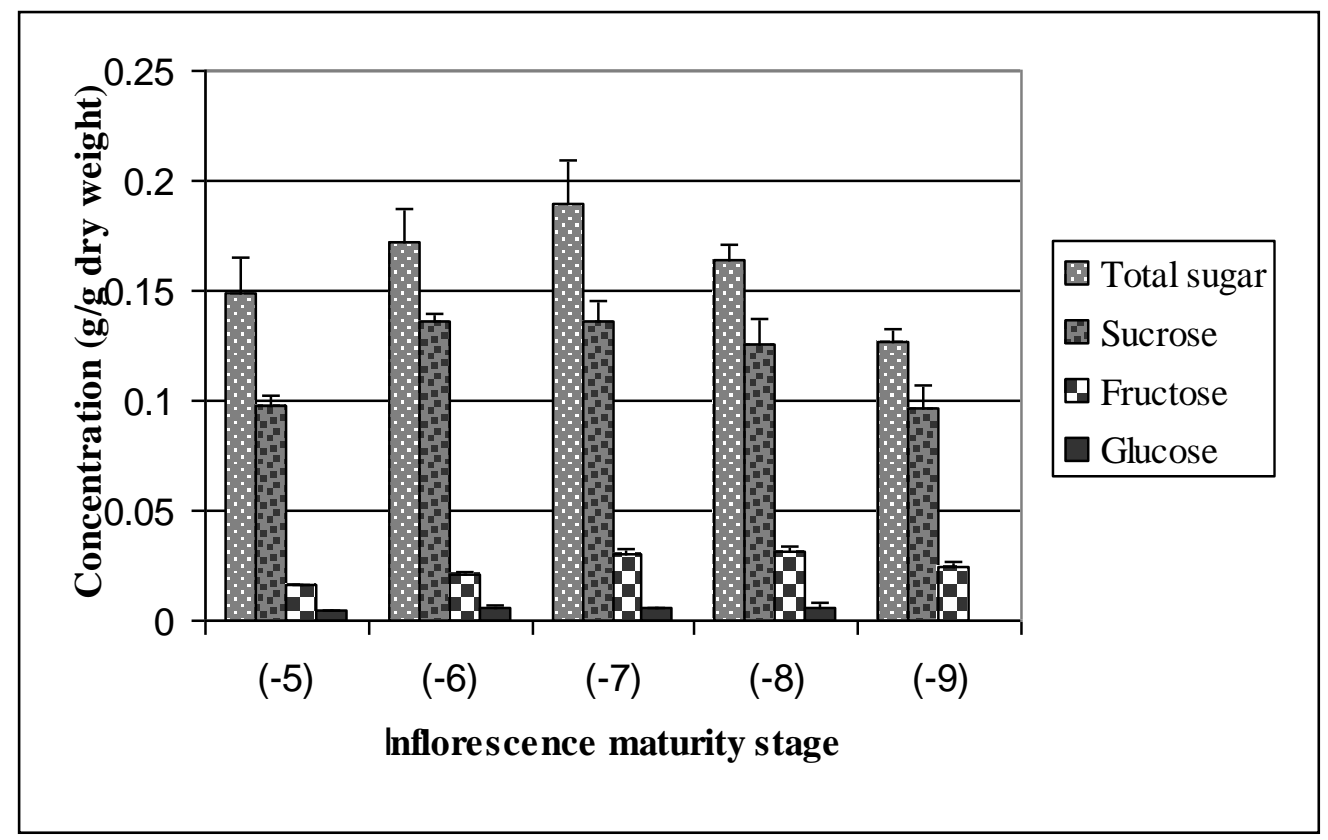

Table 1: Variation in the concentration of total sugar, proline and starch in inflorescence tissues at different stages of maturity

\begin{tabular}{|c|c|c|c|}
\hline Maturity stage* & $\begin{array}{c}\text { Mean total sugar } \\
\text { Concentration g/g DW }\end{array}$ & $\begin{array}{c}\text { Mean proline } \\
\text { Concentration g/g DW }\end{array}$ & $\begin{array}{c}\text { Mean starch } \\
\text { Concentration g/g }\end{array}$ \\
\hline
\end{tabular}




\begin{tabular}{|l|l|l|l|}
\hline & & & \multicolumn{1}{c|}{$\mathrm{DW}$} \\
\hline$-1 \quad(139.2)$ & $0.1116^{\mathrm{e}, \mathrm{f}}$ & $0.0006^{\mathrm{d}}$ & $0.1685^{\mathrm{e}, \mathrm{f}}$ \\
\hline$-2(127.7)$ & $0.1809^{\mathrm{a}, \mathrm{b}, \mathrm{c}}$ & $0.0005^{\mathrm{d}}$ & $0.1879^{\mathrm{d}, \mathrm{e}, \mathrm{f}}$ \\
\hline$-3(99.2)$ & $0.0996^{\mathrm{f}}$ & $0.0012^{\mathrm{c}, \mathrm{d}}$ & $0.1344^{\mathrm{f}}$ \\
\hline$-4(66.0)$ & $0.1296^{\mathrm{d}, \mathrm{e}, \mathrm{f}}$ & $0.0032^{\mathrm{b}, \mathrm{c}}$ & $0.2144^{\mathrm{d}, \mathrm{e}, \mathrm{f}}$ \\
\hline$-5(46.0)$ & $0.1543^{\mathrm{c}, \mathrm{d}, \mathrm{e}}$ & $0.0037^{\mathrm{b}, \mathrm{c}}$ & $0.2532^{\mathrm{c}, \mathrm{d}, \mathrm{e}, \mathrm{f}}$ \\
\hline$-6(27.5)$ & $0.1756^{\mathrm{b}, \mathrm{c}, \mathrm{d}}$ & $0.0040^{\mathrm{b}}$ & $0.3047^{\mathrm{b}, \mathrm{c}, \mathrm{d}, \mathrm{e}}$ \\
\hline$-7(18.1)$ & $0.2236^{\mathrm{a}}$ & $0.0046^{\mathrm{b}}$ & $0.2745^{\mathrm{c}, \mathrm{d}, \mathrm{e}, \mathrm{f}}$ \\
\hline$-8(11.0)$ & $0.2214^{\mathrm{a}, \mathrm{b}}$ & $0.0042^{\mathrm{b}}$ & $0.3428^{\mathrm{a}, \mathrm{b}, \mathrm{c}, \mathrm{d}}$ \\
\hline$-9(7.4)$ & $0.1873^{\mathrm{a}, \mathrm{b}, \mathrm{c}}$ & $0.0040^{\mathrm{b}}$ & $0.3382^{\mathrm{a}, \mathrm{b}, \mathrm{c}, \mathrm{d}}$ \\
\hline$-10(4.6)$ & $0.1482^{\mathrm{c}, \mathrm{d}, \mathrm{e}}$ & $0.0053^{\mathrm{a}, \mathrm{b}}$ & $0.4743^{\mathrm{a}}$ \\
\hline$-11(3.5)$ & $0.1264^{\mathrm{e}, \mathrm{f}}$ & $0.0051^{\mathrm{a}, \mathrm{b}}$ & $0.4104^{\mathrm{a}, \mathrm{b}, \mathrm{c}}$ \\
\hline$-12(3.3)$ & $0.1172^{\mathrm{e}, \mathrm{f}}$ & $0.0077^{\mathrm{a}}$ & $0.4443^{\mathrm{a}, \mathrm{b}}$ \\
\hline$-13(2.4)$ & $0.1168^{\mathrm{e}, \mathrm{f}}$ & $0.0048^{\mathrm{b}}$ & $0.4089^{\mathrm{a}, \mathrm{b}, \mathrm{c}}$ \\
\hline Significant level & $\mathrm{P}=0.0001$ & $\mathrm{P}=0.0001$ & $\mathrm{P}=0.0005$ \\
\hline CV (\%) & 21.25 & 48.19 & 36.38 \\
\hline
\end{tabular}

Values given in each column are means of 4 replicates.

* Mean length of inflorescence $(\mathrm{cm})$ corresponding to each maturity stage is given in parenthesis.

stages. The starch content of -13 stage was nearly 2 fold higher than that of -1 stage.

The importance of carbohydrates in flower bud formation has been emphasized by numerous authors (Jackson and Sweet, 1972; Bernier et al., 1993). The total sugar content exhibited remarkable differences during inflorescence development. More immature stages (-13 and -
12) had the lowest concentrations of total sugars. From -11 stage to -7 stage, the total sugar level showed a gradual increase and the highest level was observed in -7 stage. This was about 2 fold increase compared to -12 stage. Considering more mature stages ( -1 to -4$)$, the total sugar content in $-1,-3$ and -4 stages were low but a significantly higher level of total sugar was observed in -2 stage. 
The sugar profiles in maturity stages from 5 to -9 , showed that the most abundant sugar was sucrose (figure 2). Both total sugar concentration $(\mathrm{p}=0.024)$ and sucrose concentration $(\mathrm{p}=0.01)$ were significantly different among different maturity stages. Total soluble sugar concentration in -7 and -6 maturity stages were significantly higher than that of -9 stage. However, there was no significant difference between -8 and -5 stages. The sucrose concentration in -7 and -6 maturity stages was significantly higher than that of -5 and -9 maturity stages. Fructose was the second most abundant sugar component in the tested samples. Maturity stages -7 and -8 showed significantly higher levels of fructose when compared to other stages. The glucose content in the tested samples was relatively low compared to sucrose and fructose. The glucose content was significantly higher in -8 stage when compared to other maturity stages.

Distinct differences were observed among inflorescences of different maturity stages in terms of total sugar and sugars profiles. In particular, -6 to -8 stages exhibited prominent differences when compared to other stages. These differences may be attributed to specific changes in cellular processes such as cell division and cell elongation in these stages. Studies on flower development in Lilium longiflorum indicated floral organs that undergo extensive growth and elongation such as tepal, filament and style had higher sugar concentrations (Ranwala and Miller, 1998).

Previous studies have shown that very tender inflorescences (usually below stage -9) and the more mature inflorescences (usually above -4 stage) were not suitable for callus induction (data not shown). At present, explants for in vitro culture are obtained from immature inflorescences with an external spathe length of about $10 \mathrm{~cm}$ which may include -5 to -9 stages (data not shown). In this maturity range, significantly higher levels of total sugar and sucrose were observed in stages $-6,-7$ and -8 than in the other stages. The higher accumulation of these solutes in these stages may have some significance in morphogenesis, especially as an energy source. The $10 \mathrm{~cm}$ length inflorescence that responds better for callusing falls within this range. Thus total sugar and sucrose content may be possible biochemical markers for assessing the morphogenic potential of inflorescence explants.

\section{Acknowledgement}

Thanks are due to the staff of the Tissue Culture Division and Plant Physiology Division, Coconut Research Institute, Sri Lanka for the assistance in performing this investigation.

\section{References}

Baker, C. M., Fernandez, N. M and Cater, C. D. (1999) Improved shoot development and rooting from mature cotyledons of sun flower. Plant Cell, Tissue and Organ Culture 58: 39-49

Bernier, G., Havelange, A., Houssa, C., Petitjean, A., and Lejeune, P. (1993) Physiological signals that induce flowering. Plant Cell 5: 1147-1155

Branton, R. L. and Blake J., (1983) Development of organized structures in callus derived from explants of Cocos nucifera L. Annals of Botany 52: 673-678

Claussen, W. (2005), Proline as a measure of stress in tomato plants. Plant Science 168: 241-248

Cueto, C. A., Ebert, A. W., Rillo, E.P. and Orense, O.D. (1997) In vitro regeneration of coconut (Cocos nucifera L.) from immature inflorescences of tall cultivars. ISHS Acto Horticulturae 447: -

Dubois, M., Gilles, K.A., Hamilton, J. K., Rebers, P.A., and Smith, F. (1956). Colorimetric method for determination of sugars and related substances. Analytical Chemistry 28: $350-356$.

Hare, P. D., Cress, W.A., and Staden, J. van., (1999). Proline synthesis and dehydration: 
a model system for elucidating stressrelated signal transduction. Journal of Experimental Botany 50: 413-434

Hornung, R. and Verdeil J-L., (1999) Somatic embryogenesis in coconut from immature inflorescence explants In: Orapeza, C., Verdeil, J. L., Ashburner, G. R., Cardena, R. and Santamaria, J. M. (Eds), Current Advances in Coconut Biotechnology. Kluwer Academic Publishers, Dordrecht, The Netherlands, 297-309.

Ito A, Hayama H, Kashimura Y, (2002), Sugar metabolism in buds during flower bud formation; a comparison of two Japanese pear \{Pyrus pyrifolia (Burm.) Nak\} cultivars possesing different flowering habits. Scientia Horticulturae 96: 163-175.

Jackson, D.I. and Sweet, G.B. (1972), Flower initiation in temperate woody plants. Hort Abst. 42: 9-24

Olley, C.M., Joyce, D.C. and Irving, D.E., (1996) Changes in sugar, protein, respiration and ethylene in developing and harvested Geraldton waxflower (Chamelaucium uncinatum) flowers Newzealand Journal of crop and Horticultural Science 24: 143150.
Ranwala, A.P. and Miller, W.B., (1998) Sucrose- cleaving enzymes and carbohydrate pools in Lilium longiflorum floral organs. Physiologia Plantarum 103: 541-550.

Rodrigues-Otubo, B. M., Penteado, M. I. de O. and Valle, C. B. do (2000) Embryo rescue of interspecific hybrids of Brachiaria spp. Plant Cell Tissue and Organ Culture 61(3): 175-182

Samaras, Y., Bressan, R.A., Csonka, L.N., Garcia-Rios, M.G., Paino, D., Urzo, M. and Rhodes, D. Proline accumulation during drought and salinity, In: Smirnoff N. (Ed.), Environment and Plant Metabolism, Bios Scientific Publishers, Oxford, 1995. 161-187

Verdeil, J.L., Huet, C., Grosdemange, F. and Buffard-Morel, J. (1994) Plant regeneration from cultured immature inflorescence of coconut (Cocos nucifera L.): evidence for somatic embryogenesis, Plant Cell Reports 13: 218-221 